\title{
Thinking on Sustainable Development of the Integrated Rice-Crayfish Farming System in China
}

\author{
LIU Kaiwen ${ }^{1,2}$, QI Dongliang1 and ZHU Jianqiang, ${ }^{1,2 *}$ \\ ${ }^{1}$ Hubei Provincial Key Laboratory of Waterlogging Disaster and Wetland Agriculture, China
}

${ }^{2} J i n g z h o u$ Agro-meteorology Experimental Station of Hubei Province, China

*Corresponding author: ZHU Jiangqiang, Hubei Provincial Key Laboratory of Waterlogging Disaster and Wetland Agriculture, Jingzhou 434025, China

\begin{abstract}
The paper introduced specific model of integrated rice-crawfish farming, analyzed its advantages and disadvantages, as well as other relevant problems. Finally, in order to guide sustainable development for integrated rice-crawfish farming, we put forward some strategies and effective ways.
\end{abstract}

Keyword: integrated rice-crawfish farming system; advantage and disadvantage; effective measures; sustainable development

\section{Introduction}

Paddy-field-fish-culture was started in southeast Asia more than 6000 years ago $\mathrm{Hu}$ et al. [1], and its history may date back to more than one thousand years ago in southern China Lu and Li [2]. An integrated farming (stereoscopic culture) in paddy field, which mainly refers to traditional modes such as rice-fish, rice-crab, rice-crawfish symbiosis, or rice-fish-crab symbiosis and rice-fishcrawfish symbiosis, and some unique modes such as rice-duck, rice-frog, rice-turtle and so on Ahmed et al., [3]. The integrated ricecrawfish farming system, one of new-developed integrated farming in paddy field, is an important farming system and has been well practiced in China. Crawfish (procambarus clarkii) aquaculture can be developed in pond, paddy field and lotus root field, and raising crawfish in paddy field occupied approximately $75.1 \%$ of the total raising area and consequently produced $72.4 \%$ of the total crawfish in 2018. The top five provinces in the development of crawfish aquaculture are Hubei, Hunan, Anhui, Jiangsu, and Jiangxi, therein Hubei produced 812.4 thousand tons of crawfish and that accounted for about $50 \%$ of the total output in China in 2018 MARC, [4]. According to an investigation reports by statistical bureau of Hubei province, the average productivity of rice-crawfish pattern is about 45,000 RMB ha-1 greater than that of either the traditional "rice-rape rotation" or "rice-wheat rotation" system, indicating its great economic and social benefits Si et al., [5]. However, the rice-crawfish is a double-edged sword. Thus, how to draw on its advantages and avoid its disadvantages should be fully considered.

\section{Model of Integrated Rice-Crawfish Farming System}

Rice planting and crawfish breading are combined together to form a kind of farming system, namely integrated rice-crawfish farming system (IRFS) or rice-crawfish mode in China. It is necessary to do engineering reform of paddy field so that soil and water resource in that can be made the best use for rice planting and crawfish breading under the IRFS. In light of inter-annual and seasonal differences in rice plantation and crawfish aquaculture within paddy field ecosystem, an IRFS can be classified as following specific modes: rotation of rice and crawfish system (RRCS), coculture (symbiosis) of rice and crawfish system (CRCS), and continuous cropping of rice and crawfish system (CCRCS). Among these modes, the RRCS is the most popular one and has been widely practiced in China.

The RRCS refers to a mode of rice plantation alternate with crawfish aquaculture orderly in different seasons and years at the same paddy field ecosystem. In the RRCS, crawfish aquaculture is conducted after the ending of rice growing season. The key features of the RRCS are alternate in small rotation and large rotation. Large rotation means that crawfish is cultured in the paddy field after rice 
harvest until to the next year while small rotation indicates that rice is cultivated timely after crawfish captured at the end of spring, and repeating this continuously.

The CRCS refers to a production mode that crawfish is cultured in paddy field and symbiosis together with rice plants. There is an especial situation in production practice that crawfishes are only cultured in aquaculture ditch excavated along the perimeter of paddy field during rice-growing period, which also called as quasi co-culture (symbiosis) of rice and crawfish system (QCRCS). The CCRCS refers to that paddy filed is used for crawfish culture in winter leisure period, and after that the CRCS and the QCRCS are implemented during rice-growing period, which also called as a special CRCS mode under the RRCS. The CCRCS can produce a singleseason rice and two-stages crawfish or multi-period crawfish.

\section{Advantages and Disadvantages of Integrated Rice- Crawfish Farming System}

In the IRFS, rice is subject and soil is base, surface water in paddy field is used for crawfish culture. As one of typical models of eco-cycle agriculture, developing crawfish aquaculture in paddy field has become an important way to foster new kinetic energy in economic growth and to carry out targeted poverty alleviation in agricultural industry, and play an important role in boosting supply-side structural reform in agriculture(fishery), and to facilitate agricultural(fishing) efficiency and farmer income under the overall background of China government to roundly implement the strategy of rural vitalization in China. In order to sustainable and healthy development of the IRFS, we summarize its advantage and disadvantage as following.

1. The IRFS can stabilize grain production and increase economic benefit. However, farmers usually pay more attention to crawfish farming rather than rice production. A bad sign is to concern about the benefits of raising crayfish and for normal growth of rice are not to scientifically consider the need of water and fertilizer, such as deep-water irrigation, inadequate field drying, shortage of suitable technology and corresponding product in soil fertilization and improvement for rice-crawfish mode among different years.

2. The IRFS could increase soil fertility Si et al., [6]; Cao et al., [7]; Wang et al., [8], Cai et al., [9], while aggravate secondary gleying of soil under a long-term IRFS Cao et al, [7]. Compared with traditional rice monoculture model, the IRFS resulted in a high content of soil readily oxidizable organic carbon, soil total nitrogen, soil total phosphorus and soil total potassium, but leading to a dark color, a more compact structure and obvious gleying in soil Cao et al, [7]. Moreover, since soil is located in a long-term flooded status under the IRFS system, organic matter produces amass of organic acids so that lead to a reduction of soil $\mathrm{pH}$ and consequently cause mass propagation of pathogenic microorganism.

3. The IRFS may be water-saving meanwhile possibly increase water resource consumption. Crawfish farming in paddy field need for more water to store in field during crawfish aquaculture, with a function of rainwater storage and waterlogging control during rainy periods. On other hand, water consumption increase due to irrigation, water exchange and drainage during periods of little rain and when the water needed to prevent high temperature and cold damage, as well as to maintain water quality for crawfish aquaculture, under the IRFS. Also, a greater graywater discharge is yield due to frequently water exchange and drainage. In addition, 50\% 80\% of water consumption will be produced when high-yield paddy fields with low groundwater table are used or converting dry land into paddy fields for crawfish farming Xiang et al, [10].

4. The IRFS could reduce dosage of chemical fertilizer and pesticides, increase nutrient content of waterbody owing to input of crawfish feeds while raise risks of non-point source pollution and water eutrophication Mao et al., [11]. Cao [7] reported that the IRFS may reduce fertilizer cost by $79.5 \%$ and pesticide cost by $50.0 \%$, but cause a high content of total nitrogen, total phosphorus, nitrate nitrogen and ammonium nitrogen in surface water of paddy field compared with traditional rice monoculture model Mao et al., [11]; Cao et al, [7]. Moreover, heavy rainfall may aggravate the transfer and diffusion of non-point source pollution, and its range and extent, which endanger the security of ecology, food and water resource, and inhibit sustainable development of crawfish industry.

5. Blind development of the IRFS causes a reduction of fertile farmland. An original intention of popularizing the IRFS is to make rational use of liable waterlogging farmland such as low-lying land with low ground temperature, waterlogged lowland between hillocks, and degraded fishponds to increase productivity of farmland by circulation of materials within paddy field system, and to develop eco-cycle agriculture. However, the producers mainly focus on economic benefit of crawfish farming in paddy filed, and dig aquaculture ditch with large cross section that occupied $20 \% \sim 30 \%$ or more of paddy area. Moreover, even high-yield paddy fields are used or converting dryland into the IRFS, resulting in the reduction in farmland fertile.

6. a large area of IRF affects regional hydrological cycle of water use, and these influences should not be ignored $\mathrm{Li}$ et al., [12]. For example, Jingzhou, Hubei province is located in central China, a main area for crawfish farming in paddy field; with annual rainfall of $1100 \mathrm{~mm}$. Water consumption per hectare is $6390 \mathrm{~m}^{3}$ for the IRFS and $3375 \mathrm{~m}^{3}$ for middleseason rice at the Jingzhou in a normal precipitation year. Obviously, water consumption in the IRFS is much more than in the rice monoculture. Given that the contradiction between water supply and its demand becoming more prominent in this region, development scales of the IRFS should be proper controlled in the future.

\section{Sustainable Development of Integrated Rice- Crawfish Farming System}

In view of the above analysis, effective measures should be adopted to guide sustainable development of the IRFS, so that 
dealing with possible risks on ecology, environment, climate and agricultural industry.

First, as an eco-agricultural mode, the IRFS needs some certain conditions as following:

a. low terrain.

b. Clayey soil.

c. Soil pH with neutral or slightly alkaline.

d. High groundwater table.

e. Good irrigation and drainage conditions.

f. Suitable location where close to water resource.

g. a climate characterized by warm and wet with abundant precipitation or water resource.

Hence, agricultural producers should adjust measures based on local conditions and avoid blind development of the IRFS.

Second, in the region where is suitable for development of the IRFS, local government and agricultural producers should appropriately control the scale of the IRFS. Because development of this mode needs a lot of water resources, and induce risks of environmental and ecological issues. Therefore, coordinating development of crawfish industry and ecological environmental production need to strengthen feasibility study of climatic environment. And, proper development of the IRFS within the scope of carrying capacity of ecoclimatic resource, and scientifically evade climatic and ecological risks caused by an unbalance of industrial scale and ecoclimatic resource.

Third, based on problems existed in the production, the IRFS mode needs to be optimized. Here something should be done that:

1) constructing proper farmland works for water circulation self-purification.

2) Reducing crawfish bait in autumn and winter by returning all straw to field.

3) Planting grass in early spring, putting appropriate fodder in spring and summer, reducing fertilizer application.

4) Selecting suitable rice variety and adaptive cultivation techniques to improve utilization of light and temperature resources.

5) Regulating the use of the inputs of fertilizer, fodder, pesticides and so on so that can decrease potential safety hazard and lower eco-environmental risks.

Fourth, water and fertilizer management in the IRFs is different from that in the rice monoculture. It is important to scientifically regulate water and fertilizer, especially for the special fertilizer and fertilizing techniques. For the CRCS mode, surface water depth in paddy field have to meet the need for crawfish moving among the rice plants, and suitable one is about $5-10 \mathrm{~cm}$ in the middle and later stages of rice growth Huang et al., [13]. However, water depth in the paddy field is not allowed to over the waterlogged resistance depth of rice plant. On the other side, although crawfish are allowed to climb into paddy field later more than ten days after fertilization, the fertilization may cause a high nitrogen content and a low dissolve oxygen, which are harmful to crawfish breeding. During crawfish aquaculture, water management is carried out in light of weather situation and water quality, water depth in paddy field 10$50 \mathrm{~cm}$, transparency about 30-40 cm, pH 7.8 8.6, dissolved oxygen more than $4 \mathrm{mg} \mathrm{L}^{-1}$, ammonia nitrogen less than $0.5 \mathrm{mg} \mathrm{ml}^{-1}$, nitrite nitrogen less than $0.02 \mathrm{mg} \mathrm{ml}^{-1}$, and sulfide less than $0.1 \mathrm{mg} \mathrm{ml}^{-1} \mathrm{Xu}$ et al., [14].

Fifth, it is needed to provide technical training and technical support to agricultural producers by integrating resources from agriculture, meteorology and aquatic product sectors, so that to raise the technical levels of farmers. In addition, it is suggested to popularize agrometeorological insurance in order to effectively transfer the risk of crawfish farming caused by meteorological disaster.

\section{Acknowledgement}

This work is supported by Hubei provincial special fund for agricultural science and technology innovation(2018skjcx01), the Engineering Research Center of Ecology and Agricultural Use of Wetland, Ministry of Education (KFT201904), and the national key research and development program of China(2016YFD0800500).

\section{References}

1. Hu L, Tang J, Zhang J (2015) Development of rice-fish system: Today and tomorrow. Chinese Journal of Eco-Agriculture 23(3): 268-275.

2. Lu Li X (2006) Review of rice-fish-farming systems in China-one of the globally important ingenious agricultural heritage systems (GIAHS). Aquaculture 260(1): 106-113.

3. Ahmed N, Allisn E H, Muir J E(2010) Rice fields to prawn farms: a blue revolution in southwest Bangladesh? Aquaculture International 18(4): 555-574.

4. Ministry of Agriculture and Rural Affairs of Peoples' Republic China (MARC) (2019). Report on the development of the crayfish industry, China.

5. Si GH, Yuan J F, Xu XY (2018) Effects of an integrated rice-crayfish farming system on soil organic carbon, enzyme activity, and microbial diversity in waterlogged paddy soil. Acta Ecologica Sinica 38: 29-35.

6. Si GH, Peng CL, Xu XY (2016) Effects of rice-crayfish integrated mode on soil microbial functional diversity and fertility in waterlogged paddy field. Soils (3): 503-509.

7. Cao CG, Jiang Y, Wang JP, Yuan PL, Chen SW (2017) Dual character of ricecrayfish culture and strategy for its sustainable development. J Chinese Journal of Eco-Agriculture 25(9): 1245-1253.

8. Wang G, Su Z, Liu D (2017) Study on spatial variation of soil nutrient in rice-crayfish co-cropping and fertilization technology of middle rice. Modern Agricultural Science and Technology (2): 160-162.

9. Cai C, Li G, Zhu J (2019) Effects of Rice-crawfish Rotation on Soil Physicochemical Properties in Jianghan Plain. Acta Pedologica Sinica 56(01): 217-226.

10. Xiang J L, Chen C, Huang H (2016) Evaluation of comprehensive benefits of agricultural heritages in fish culture in the rice field. Research on Heritages and Preservation 1(5): 111-117. 
11. Mao Z, Ding F, Zhou X (2015) Evaluation of water quality in the rotation of rice and crayfish (procampius kirschner). Scientific Fish Farming (3) 52-53.

12. Li S L, Zhang H L, Liu M X (2017) Characteristics of soil water transport and holding capacity in paddy and inner field-bund transition zones. Journal of Soil and Water Conservation 31(2): 122-128.
13. Huang F, Mi C, Wang F (2016) The advantages and comprehensive supporting techniques of rice-crayfish co-cropping. Northern Rice 46(2): 43-45.

14. Xu W, Qian L (2017) Rice-crawfish symbiotic farming. Fishery Guide to be Rich (18): 38-40.

\section{(2) (1) \\ This work is licensed under Creative \\ Commons Attribution 4.0 License}

To Submit Your Article Click Here: Submit Article

DOI: $10.32474 / C I A C R .2020 .08 .000289$

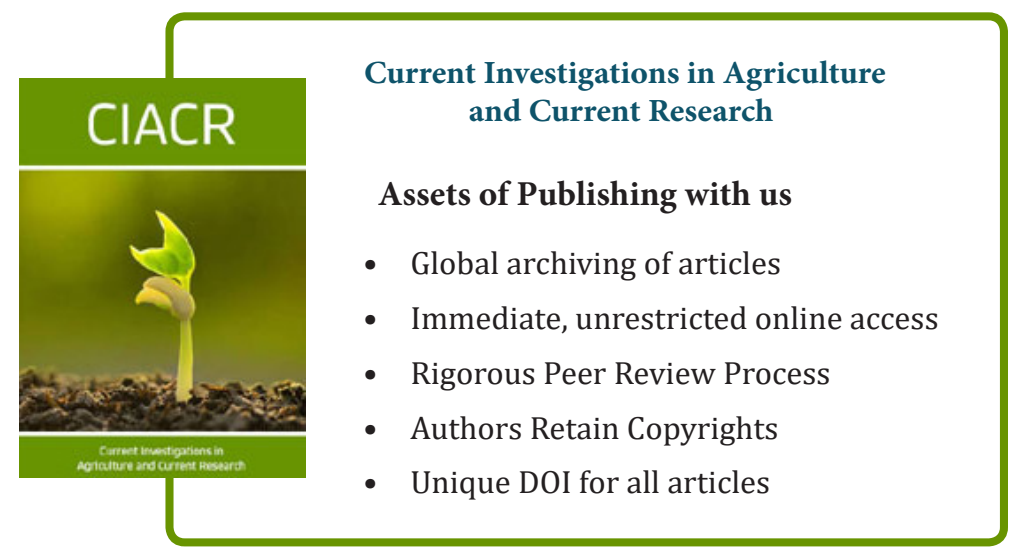

